\title{
ETHICS AND LAW
}

\section{Personalized Genomics}

\author{
Saad Ahmed (Meds 2016) \\ Faculty Reviewer: Dr. Rob Hegele, MD, FRCPC, FACP, FAHA, FCAHS
}

A growing number of doctors have reported patients arriving at their offices with genotyping results or even readouts of their partially sequenced genome. ${ }^{1}$

The advent of commercial direct-to-consumer (DTC) genetic testing has made such scenarios not uncommon. For only $\$ 100$, companies such 23 andMe will send customers a kit to collect their saliva from which the company will sequence certain segments of the customer's genetic code (also known as non-targeted genetic profiling genotyping). This genotype will be uploaded to the customers' private account on the company's website, with which they will able to see their results and their risks for developing certain diseases. It is important to distinguish these types of DTC tests from what are known as whole-genome sequencing (WGS) tests. WGS tests sequence the entire genome, a feat that can now be accomplished in under a week and for under $\$ 10000 .^{2}$ WGS tests can also be DTC; however they are not as common-place due to the high cost and the limited knowledge about interpreting whole genome sequences. Non-targeted genetic profiling (NGP) tests genotype consumers' genetic information - that is, that they look for single nucleotide polymorphisms (SNPs) in certain segments of the genome that estimate the risk of a certain disease, usually by comparing it to other genetic profiles which are linked to case-control studies in which the patient's disease status was determined at the time of the study. However, most of these SNPs only predict slight increases in disease susceptibility. These SNP-based genotypes are known as non-targeted genetic profiling and their clinical utility is questionable at best. ${ }^{3}$

Many health professionals, including family doctors, do not feel comfortable dealing with such scenarios. Reasons include a lack of exposure to genomics in medical education as well as the tremendous difficulties in objectively predicting disease from any genomic sequence or genotype. ${ }^{4,5}$ One report recently referred to NGP genetic tests as 'fortune telling reports., ${ }^{3,6}$ Indeed, in the United States a study found that only just over half of specialists in clinical genetics who had seen patients as a result of NGP tests judged the test to be clinically useful. ${ }^{1}$ Part of the problem is the manner in which NGP tests are analyzed. For instance, a recent review of two prominent NGP tests noted that they did not focus on diseases for which high-risk marker predictions were available, and instead chose to report on diseases for which genetic markers only added a modest increase in risk. ${ }^{7}$ The clinical importance of such reporting is unclear, partly because the genetic markers themselves do not account for $100 \%$ of the genetic heritability of a disease. ${ }^{7}$ There is also a lack of consensus amongst companies about the markers to use for diseases, and two tests from different companies could thus give two very different risk estimates for a disease. ${ }^{7}$ Commissions on NGP testing in the UK and US have also found that there were no follow-up systems in place to ensure proper interpretation of test results by patients and physicians. ${ }^{8}$

\section{ETHICS}

The ethical issues converge for both forms of DTC testing WGS and NGP. Both forms of testing suffer from an overload of information and an impossibility of deciphering the actual risk of disease, which in turn cause problems with informed consent. As explained above, this means that the clinical validity and utility of NGP and commercial WGS tests are questionable at best, and thus the use of NGP testing as a screening tool is problematic. All screening programmes need to undergo a risk-benefit analysis to minimize the potential of unnecessary testing and treatment. ${ }^{9}$ The World Health Organization has an entire list of criteria for effective screening programmes, one of which is that the screening test be able to detect a clinically relevant disease for which effective treatment is available. ${ }^{10}$ Furthermore, the ethical principles of nonmaleficence and beneficence require that health professionals strive to minimize harm and promote the well-being of their patients. Insofar as NGP and WGS testing lead to unnecessary testing and treatment, health professionals should strive to educate patients about the truth of the tests, including both the benefits and pitfalls. Education is especially pertinent, since many NGP testing companies claim to offer the tests solely for interests' sake, and yet will report on the genetic predisposition to diseases as serious as breast cancer or Alzheimer's Disease. ${ }^{11}$

The advent of DTC testing also raises questions about social justice. Although doctors consciously minimize requests for unnecessary tests, individuals getting DTC tests could feasibly pressure their doctors into getting the extra tests done to allay those concerns, and thus drain health care resources. Furthermore, the fact that the patients can pay for the DTC tests in the first place means that they certainly are not poor, which means that affluent people who are ordering such tests will use the health care system disproportionately in comparison to those who are less affluent. ${ }^{12}$

In WGS tests, issues of privacy, obligations and future uses of data pose significant questions. For example, there can be unintended research results, such as an association found between race and IQ, which the test subjects might have not consented to. This calls for regulation and oversight of the obligations that researchers owe to the original test subjects. ${ }^{13,14}$ This specifically and recently became an issue when the NGP testing company 23andMe utilized consumer genotypic data and surveys to develop and patent a method to detect Parkinson's Disease. The company mentions in fine print that they would own all customer genetic data; still, the 


\section{ETHICS AND LAW}

consumers whose data were used for the study obviously felt the need for reimbursement. ${ }^{15,16}$ Private ownership of genetic information also raises the question of whether such data can be bought or sold. ${ }^{11}$

\section{POLICIES/LAW}

Various societies have formulated responses to DTC testing. The American Society for Human Genetics says that there should be government oversight and regulation of DTC tests, including testing the clinical validity of the claims of the tests. The companies offering them should be totally transparent and offer all the possible information in an accessible manner. ${ }^{17}$ An editorial in the BMJ called for an international industry certification of DTC tests, ${ }^{1}$ with the understanding that an Internet-based industry needs global regulation. Similarly, other pieces have argued for more oversight, regulation and certification of genetic testing labs to ensure the quality of commercial genetic testing, ${ }^{11}$ and to work towards common standards amongst DTC testing companies. ${ }^{7}$

Many European countries, such as France, Belgium, Germany, the Netherlands and Switzerland have adopted legislation curtailing DTC tests and allowing predictive genetic tests only on the request of a health professional. ${ }^{18}$ Each country still has its own approach to DTC tests. For instance, the Netherlands has a framework protecting individuals against screening tools that are clinically useless and that may pose a threat to health. Future regulation of DTC testing in the Netherlands specifically could be built upon such provisions. ${ }^{18}$ In the United Kingdom, the Human Tissue Act criminalizes the analysis of genetic information without consent, ${ }^{18}$ which means the policies with which 23andMe was able to utilize consumer genotypes would have to be carefully explained to all of their customers so as to ensure that the customers were fully consenting to their genetic information being collected and analyzed.

Currently, the United States has the Genetic Information Nondiscrimination Act, which prohibits employers and insurance companies from using genetic information. However, Canada has no such laws regarding the use of genetic information by insurance companies for underwriting. The Privacy Commissioner of Canada thus requested two papers on the subject, both of which advocated for a ban on using any genetic information in health and life insurance policies. This also included monogenic disorders, as the papers argued that they were very rare and would have a limited financial impact on insurance companies. ${ }^{19}$

\section{REALITY CHECK}

It is important to ask at this point - are health and specifically health information a "consumption good"? ${ }^{11}$ And what sort of future does this predict for the patient-physician relationship? On the surface of it, noted philosopher Ivan Illich's critique of modern society becoming increasingly "medicalized" certainly rings true, where people increasingly see their life problems as medical problems. It is also important to add a dose of reality here - genetics is not destiny. ${ }^{20}$

A recent series of articles in the CMAJ deal with the hyperbole surrounding personalized genomics. Simply put, just as the original Human Genome Project was unable to find exact genetic bases for diseases, sequencing individual genomes is unlikely to reveal answers easily. The phenomenon of incomplete penetrance, in which a genetically inherited condition may not manifest itself phenotypically due to environmental factors, highlights how non-genetic factors play a significant role in the development of any disease process. The environment and the genome also intersect in the epigenome, heritable changes to DNA that do not involve base pair sequences and can occur due to environmental stresses. This of course further complicates the correlation of a genetic mutation with a disease. ${ }^{21-25}$

The crux of the matter is that while sometimes genetic sequencing can reveal genetic mutations that are associated with a high risk of disease - as in the case of Huntington's Disease and other monogenic, heritable diseases, or even the BRCAl/2 susceptibility genes for breast cancer - at other times they do not. In other contexts still, as in the case of pharmacogenetics, it can provide useful information about a patient's response to drugs that would prevent allergic reactions or aid in drug dosing. Unfortunately, as with most things it will take time and experience to fully flesh out the ethical and legal ramifications of DTC testing. ${ }^{26}$ As health professionals we will have to keep in mind our duties to our patients' well-being and question the clinical value of advances in genetic testing that emerge in the future.

\section{REFERENCES}

1. Hauskeller C. Direct to consumer genetic testing. BMJ. 2011 Apr;342

2. Wetterstrand KA. Cost per genome [Internet]. Washington: National Human Genome Research Institute, 2013 [cited 2013 Jun 17]. Available from http://www.genome.gov/images/content/cost_per_genome.jpg

3. Bunnik E, Schermer M, Janssens AC. Personal genome testing: Test characteristics to clarify the discourse on ethical, legal and societal issues. BMC Med Ethics [Internet]. 2011;12(1):11. Available from: http://www.biomedcentral.com.proxy2.lib. uwo.ca/1472-6939/12/11

4. Brett GR, Metcalfe SA, Amor DJ, Halliday JL. An exploration of genetic health professionals' experience with direct-to-consumer genetic testing in their clinical practice. Eur J Hum Genet [Internet]. 2012 Aug [cited 2013 Jun 17];20(8):825-30

5. Mainous A, Johnson S, Chirina S, Baker R. Academic family physicians' perception of genetic testing and integration into practice: A CERA study. Fam Med. 2013 Apr;45(4):257-62. 


\section{ETHICS AND LAW}

6. Siest G. Systems biology and personalized prevention. Pers Med. 2009 May;6(3):265-8.

7. Ng PC, Murray SS, Levy S, Venter JC. An agenda for personalized medicine. Nature. 2009 Oct;461(7265):724-6.

8. Henegan JC Jr, Robin NH. Direct-to-consumer genetic testing. Curr Opin Pediatr. 2010 Dec;22(6):685-6.

9. Schrijver I, Galli SJ. Between hype and hope: whole-genome sequencing in clinical medicine. Pers Med. 2012 May;9(3):243-6.

10. Andermann A, Blancquaert I, Beauchamp S, Déry V. Revisiting Wilson and Jungner in the genomic age: a review of screening criteria over the past 40 years. Bull World Health Organ [Internet]. 2008 Apr [cited 2013 Jun 17]; 86(4):241-320. Available from: http://www.who.int/bulletin/volumes/86/4/07-050112/ en/

11. Udesky L. The ethics of direct-to-consumer genetic testing. Lancet. 2010 Oct;376(9750):1377-8.

12. Genetic and Genome-Wide Testing on Internet [Internet]. Vienna: Austrian Bioethics Commission (Austria); 2010 May 10 [cited 2013 Jun 17]. 40 p. Available from: http://www.bka.gv.at/ DocView.axd?CobId=40383

13. McGuire AL, Caulfield T, Cho MK. Research ethics and the challenge of whole-genome sequencing. Nat Rev Genet. 2008 Feb;9(2):152-6.

14. Cambon-Thomsen A. The social and ethical issues of post-genomic human biobanks. Nat Rev Genet. 2004 Nov;5(11):866-73.

15. Allyse M. 23 and me, we, and you: direct-to-consumer genetics, intellectual property, and informed consent. Trends Biotechnol. 2013 Feb;31(2):68-9.

16. Howard HC, Knoppers BM, Borry P. Blurring lines. EMBO Rep. 2010 Aug;11(8):579-82.

17. Hudson K, Javitt G, Burke W, Byers P, American Society of Human Genetics Social Issues Committee. ASHG Statement* on direct-to-consumer genetic testing in the United States. Am J Hum Genet. 2007 Sep; 81(3):635-7.

18. Borry P, van Hellemondt RE, Sprumont D, Jales CF, Rial-Sebbag E, Spranger TM, Curren L, Kaye J, Nys H, Howard H. Legislation on direct-to-consumer genetic testing in seven European countries. Eur J Hum Genet. 2012 Jul;20(7):715-21.

19. Office of the Privacy Commissioner of Canada. Genetic information, the life and health insurance industry and the protection of personal information: framing the debate [Internet]. Ottawa: Office of the Privacy Commissioner of Canada; 2012 Dec 21 [cited 2013 Jun 17]. Available from: http://www.priv. gc.ca/information/research-recherche/2012/gi_intro_e.asp 20. Rosoff PM. The myth of genetic enhancement. Theor Med Bio- eth. 2012 Jun;33(3):163-78.

21. Collier R. Separating hype from reality in the era of the affordable genome. CMAJ. 2012 April 03;184(6):E287-8.

22. Collier R. Popping the genetics bubble. CMAJ. $2012 \mathrm{Apr}$ 3;184(6):637-8.

23. Collier R. Who should hold the keys to your DNA? CMAJ. 2012 Apr 3;184(6):638-40.

24. Collier R. Race and genetics in the doctor's office. CMAJ. 2012 Apr 17;184(7):752-3.

25. Collier R. The downside of genetic screening. CMAJ. 2012 May 15;184(8):862-4.

26. Soden SE, Farrow EG, Saunders CJ, Lantos JD. Genomic medicine: Evolving science, evolving ethics. Pers Med. 2012 July;9(5):523-8.v 